eCommons@AKU

March 2006

\title{
The growing burden of chronic kidney disease in Pakistan
}

Tazeen H. Jafar

Aga Khan University, tazeen.jafar@aku.edu

Follow this and additional works at: https://ecommons.aku.edu/pakistan_fhs_mc_med_nephrol Part of the Nephrology Commons

\section{Recommended Citation}

Jafar, T. H. (2006). The growing burden of chronic kidney disease in Pakistan. The New England Journal of Medicine, 354(10), 995-997. Available at: https://ecommons.aku.edu/pakistan_fhs_mc_med_nephrol/47 
chiatric assessment suffices, the Court has said, to take account of prisoners' "medical interests" and civil liberties, as well as the government's interest in prison safety and securing defendants' competence to stand trial.

The Court's deference to medical authority has drawn fire from dissenting justices on both the left and the right. With regard to the treatment of prisoners, Justice John Paul Stevens criticized the Court for withholding procedural safeguards, allowing psychiatrists to conflate therapeutic and security purposes, and thereby enabling them to medicate inmates for "institutional convenience" under therapeutic cover. And Justice Antonin Scalia has repeatedly insisted that the purposes of medicine are not for the profession to decide. Scalia's dissent in Gonzales v. Oregon (joined by Chief Justice John Roberts) drew a bright line between the profession's technical expertise and social role. The latter, he says, is a matter of "public morality," the province of elected officials.

Will Scalia's view gain traction? He has already brought the new chief justice on board, and many expect Justice Samuel Alito to concur with Scalia, Roberts, and Justice Clarence Thomas on questions of public morality, including those that implicate medicine. For some, this is a chilling prospect, portending an era of Big Brother intrusion into the doctorpatient relationship. For others, the promise is one of democratic empowerment - the making of moral choices by popularly chosen leaders instead of technocratic elites.

We may soon learn whether Scalia's perspective will prevail. The justices' decision last month to consider a congressional ban on so-called partial-birth abortion poses the question of medicine's authority in stark form. Six years ago, the Court struck down a similar state law because it lacked an exception for maternal medical need. But Congress tried an end run around this ruling, in the form of a "finding" that such abortions are "never medically necessary." Physicians who perform abortions say otherwise. Lower courts have deferred to their views, dismissing this "finding" as unreason- able and concluding that the congressional ban is unconstitutional.

Proponents of the ban insist that Congress, not the medical profession, is entitled to deference on the question of clinical need. Abortion-rights advocates counter that pregnant women's health needs are for them and their doctors to determine. Central to the latter claim is the premise that the medical judgment to which a woman is entitled encompasses the moral dimensions of the decision to abort. Should the former view prevail, public authority over medicine's morality and purposes will greatly expand. The justices would do well to weigh the consequences for caregivers' ability to address patients' varying needs.

Dr. Bloche is professor of law at Georgetown University and a visiting fellow at the Brookings Institution, both in Washington, D.C., and adjunct professor at Bloomberg School of Public Health, Johns Hopkins University, Baltimore.

1. Bloche MG. Medical ethics in the courts. In: Danis M, Clancy C, Churchill LR, eds. Ethical dimensions of health policy. New York: Oxford University Press, 2002:133-56. 2. Henderson JA Jr, Siciliano JA. Universal health care and the continued reliance on custom in determining medical malpractice. Cornell Law Rev 1994;79:1382-404.

\section{The Growing Burden of Chronic Kidney Disease in Pakistan}

Tazeen H. Jafar, M.D., M.P.H. ical attention and was found to have a serum creatinine concentration of $5.2 \mathrm{mg}$ per deciliter (460 $\mu \mathrm{mol}$ per liter), a blood urea nitrogen concentration of $87 \mathrm{mg}$ per deciliter ( $31 \mathrm{mmol}$ per liter), an estimated glomerular filtration rate (GFR) of $10 \mathrm{ml}$ per minute per $1.73 \mathrm{~m}^{2}$ of body-surface area, urinary albumin excretion of $1.5 \mathrm{~g}$ per day, and mildly shrunken kidneys. Twice-a-week sessions of hemodialysis were initiated, but the patient had to take out a loan to pay for them and soon was unable to afford to continue treatment. He has been lost to followup ever since.

Given pressing medical concerns such as infectious diseases and malnutrition faced by developing countries, why should we even talk about chronic kidney disease in such places? The fact is that many developing countries are facing a silent epidemic of 
chronic kidney disease - one facet of the health transition associated with industrialization. Moreover, by virtue of its progression to kidney failure and its association with accelerated cardiovascular disease, chronic kidney disease has profound effects on morbidity, mortality, and health care costs, as well as important social implications.

Representative estimates of the burden of chronic kidney disease (defined as a decrease in the GFR to less than $60 \mathrm{ml}$ per minute per $1.73 \mathrm{~m}^{2}$ - half the normal rate - or the presence of albuminuria for three or more consecutive months) in most developing countries are lacking. However, data from community-based studies in Pakistan reveal an alarmingly high burden. Approximately 15 to 20 percent of persons 40 years of age or older have a reduced estimated GFR. ${ }^{1}$ Although GFR estimation equations have not been validated in Asian populations, such a burden is consistent with the high prevalence of diabetes and hypertension, the two main risk factors for chronic kidney disease. The prevalence of diabetes in countries of the Indian subconti-

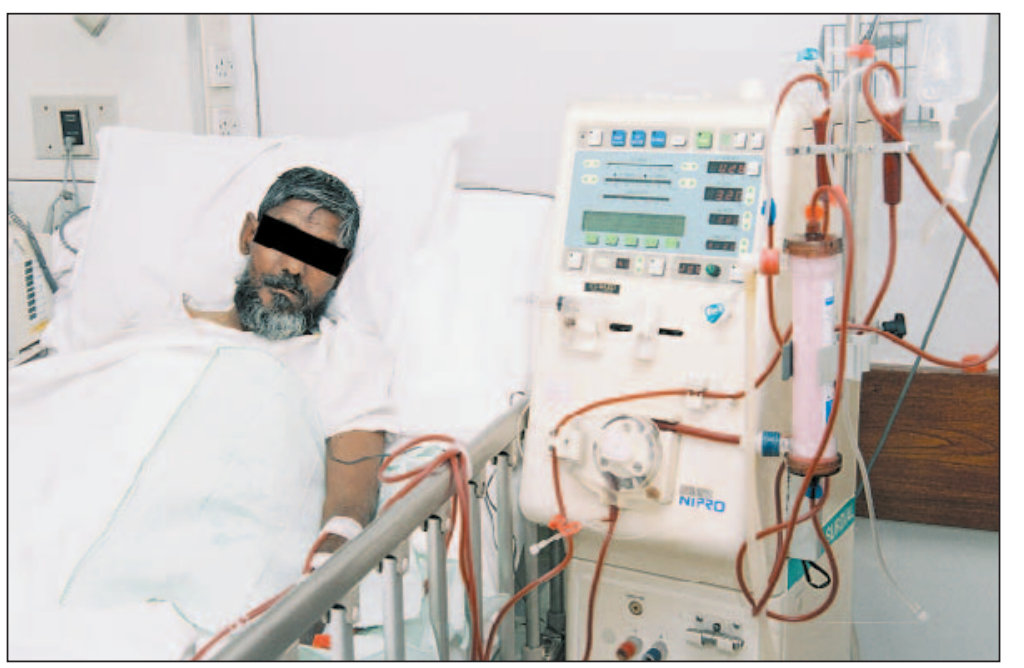

A Patient with Kidney Failure Undergoing Hemodialysis at the Aga Khan University Hospital, Karachi, Pakistan.

nent (about 20 percent among persons 40 years of age or older) is two to three times that reported in Western countries and is projected to triple over the next two decades. Evidence indicates that chronic kidney disease develops in about a third of patients with diabetes. The burden of hypertension is even higher - affecting about one third of Pakistanis 45 years of age or older, according to the 1990-1994 National Health Survey of Pakistan.

These troubling rates are fueled in part by diets high in partially hydrogenated vegetable oil and low in fresh produce, as well as by increases in sedentary lifestyles in low-income communities, where children spend an average of four to six hours per day watching television. Moreover, Pakistani children have higher blood-pressure levels, adjusted for body-mass index, than white children in the United States ${ }^{2}$ - and childhood levels have been shown elsewhere to predict levels in adulthood. Moreover, populations in which low birth weight and malnutrition are common may be predisposed to chronic diseases associated with weight gain. ${ }^{3}$
Despite these predisposing conditions, screening for and early detection of chronic kidney disease, particularly in high-risk patients with hypertension and diabetes, remain grossly inadequate. In part, this failure may be attributed to the fact that the health care systems in developing countries are geared toward providing shortterm, symptomatic treatment. But perhaps an even greater problem is that these high-risk patients remain largely unidentified. Although the average Pakistani adult visits a primary care physician four to five times each year, 64 percent of adults have never had their blood pressure measured, and 70 percent of patients with hypertension and 50 percent of patients with diabetes are unaware of their condition. ${ }^{4}$ Compounding the problem of underdetection are gaps in the knowledge of some Pakistani physicians about the management of hypertension and diabetes, which lead to undertreatment and a lack of preventive measures against chronic kidney disease.

Against this backdrop of poor medical practices, patients with kidney failure are faced with the high cost of renal-replacement therapy. On the Indian subcontinent, where the per capita annual income (calculated in U.S. dollars) is about $\$ 400$, the cost of dialysis is about $\$ 4,000$ per year. Kidney transplantation costs about $\$ 5,000$, and post-transplantation medications cost $\$ 2,000$ annually. Thus, treating kidney failure is an unaffordable proposition for public health systems that receive 0.8 to 4 percent of the gross national product (as compared with 10 to 15 percent in developed countries). These hard facts, coupled with the general lack of third-party health insurance, mean that less 
than 10 percent of patients with kidney failure receive any kind of renal-replacement therapy. Although the number of hemodialysis centers is increasing in many regions of Pakistan, most patients who begin to receive dialysis die or stop treatment within the first three months because of cost constraints. Kidney transplantation is the cheaper option, but only about 5 percent of patients with kidney failure receive a transplant. The shortage of donors is a universal problem, and paid organ donation accounts for 70 percent of all transplantations in Pakistan.

Clearly, programs to prevent chronic kidney disease and to treat it in the earliest stages must be designed and integrated into the existing health care infrastructure. The World Health Organization's Innovative Care for Chronic Conditions Framework provides a model for redesigning health care systems in accordance with local resources. The framework emphasizes a well-defined care plan, self-care, scheduled followup appointments, monitoring of outcomes, adherence, and stepwise treatment protocols delivered mainly by primary care practitioners. However, increased referrals from such programs, even if limited to patients with advanced disease, may place excessive de- mands on existing nephrology services. At present, there are only about 80 formally trained nephrologists in Pakistan for a population of about 160 million (the United States has more than 5000 nephrologists for a population of about 300 million). Capacity-building efforts are therefore needed to train physicians in this specialty.

Until the public health services in Pakistan are developed further, private primary care practitioners will continue to be the frontline caregivers in Pakistan. These physicians should be required perhaps even as a prerequisite for the renewal of licensure - to participate in continuing medical education programs regarding the management of hypertension, diabetes, and chronic kidney disease.

Ideally, developing countries would have access to ample resources to set up large-scale, integrated programs for the prevention and treatment of chronic diseases, as well as dialysis and transplantation units for patients with kidney failure. But in reality, such resources are unlikely to be found. Low-income countries must therefore shift their emphasis from renal-replacement therapy to more cost-effective preventive services, recognizing that questions of social justice and equity will inevitably arise. Since Pakistan's resources are currently being directed toward the rehabilitation of survivors of October's earthquake, it is unlikely that more resources will be allocated for the treatment or prevention of chronic kidney disease anytime soon. International agencies must therefore recognize that without urgent attention to the problem, the adverse consequences of hypertension, diabetes, and chronic kidney disease will bring untold misery to the next generation of inhabitants of the Indian subcontinent - who represent one sixth of the world's population.

Dr. Jafar is the head of the section of nephrology, director of the clinical epidemiology unit, and an associate professor of medicine and community health sciences at Aga Khan University, Karachi, Pakistan, and an adjunct faculty member at TuftsNew England Medical Center, Boston.

1. Jafar TH, Hatcher J, Chaturvedi N, Levey AS. Prevalence of reduced estimated GFR (eGFR) in Indo Asian population. J Am Soc Nephrol 2005;16:323A. abstract.

2. Jafar TH, Islam M, Poulter N, et al. Children in South Asia have higher body massadjusted blood pressure levels than white children in the United States: a comparative study. Circulation 2005;111:1291-7.

3. Bhargava SK, Sachdev HS, Fall CHD, et al. Relation of serial changes in childhood bodymass index to impaired glucose tolerance in young adulthood. N EnglJ Med 2004;350:86575.

4. Ahmad K, Jafar TH. Prevalence and determinants of blood pressure screening in Pakistan. J Hypertens 2005;23:1979-84.

\section{Chronic Kidney Disease in the Developing World}

\section{Rashad S. Barsoum, M.D.}

The attention being paid globally to chronic kidney disease is attributable to five factors: the rapid increase in its prevalence, the enormous cost of treatment, recent data indicating that overt disease is the tip of an iceberg of covert disease, an appreciation of its major role in increasing the risk of cardiovascular disease, and the discovery of effective measures to prevent its progression. These factors render chronic kidney disease an important focus of health care planning even in the developed world, but the problems they delineate in the developing world are far more challenging. Some 85 per- cent of the world's population live in low-income or middle-income countries, where the clinical, epidemiologic, and socioeconomic effects of the disease are expected to be the greatest.

Data from the United States suggest that for every patient with end-stage renal disease (ESRD), 